\author{
АНАТОЛИЙ КУЛАГИН \\ Государственный социально-гуманитарный университет \\ Кафедра литературы \\ 140410 Коломна Московской обл. \\ ул. Зелёная, 30 \\ litkaf@mail.ru
}

\title{
НЕИЗВЕСТНОЕ СТИХОТВОРЕНИЕ ГЕННАДИЯ ШПАЛИКОВА
}

\author{
AN UNKNOWN POEM \\ BY GENNADY SHPALIKOV
}

В статье впервые публикуется стихотворение Геннадия Шпаликова Баллада про тихое отчаяние, посвященное кинорежиссеру Ларисе Шепитько. Стихотворение сохранилось в составе письма Шпаликова к Шепитько и датируется концом 1960-х годов. Автор статьи рассматривает основные мотивы публикуемого стихотворения и ставит его в контекст творчества кинодраматурга и поэта, обнаруживает переклички с другими его лирическими произведениями и сценариями.

Ключевые слова: Геннадий Шпаликов, стихотворение, архив, мотив, контекст.

Gennady Shpalikov's poem "Ballada pro tikhoye otchayanie” ('A Ballad About a Quiet Despair'), dedicated to film director Larisa Shepitko, is hereby published for the first time. The piece survived as part of Shpalikov's letter to Shepitko dating from the 1960s. The author of the article examines key motifs of the poem and places it in the context of the whole output of the scenarist and poet, showing how it reverberates with his other lyrical pieces as well as screenplays.

Translated from the Russian by Marta Kaźmierczak

Keywords: Gennady Shpalikov, poem, archive, motif, context.

Поэтическое творчество Геннадия Шпаликова (1937-1974), при жизни автора не имевшее выхода к читателю, представлено ныне наиболее полно в трех, почти синхронно появившихся на исходе ушедшего столетия, изданиях, подготовленных соответственно Ю. Файтом 
и А. Нехорошевым ${ }^{1}$. Несмотря на всю основательность проделанной ими работы, возможности поиска и обнаружения неизвестных доселе поэтических текстов Шпаликова еще не исчерпаны. Нам удалось обнаружить стихотворение поэта, не вошедшее пока ни в одну из книг и журнальных публикаций ${ }^{2}$

Оно называется Баллада про тихое отчаяние и дошло до нас в составе письма Шпаликова, адресованного кинорежиссеру Ларисе Ефимовне Шепитько (1937-1979); ей же стихотворение и посвящено. С ней, своей ровесницей и выпускницей того же вуза, где учился сам (ВГИК), а также с ее мужем, кинорежиссером Элемом Климовым, - Шпаликов был дружен, о чем свидетельствует уже тон письма («Лара! привет!» и так далее), не говоря о доверительном характере его содержания. Письмо хранится в Российском государственном архиве литературы и искусства (ф. 3095, оп. 1, ед. хр. 784). Оно тематически связано с совместной работой автора письма и его адресата над сценарием фильма $T b l u$ я. В архиве письмо условно датировано 1968 годом; ознакомившийся по нашей просьбе с содержанием письма друг Шпаликова, сценарист П. К. Финн, в письме упомянутый, полагает, что оно относится к концу февраля или марту 1969 года ${ }^{3}$. Стихотворение же могло быть написано непосредственно перед письмом, но могло быть написано и раньше; думается поэтому, что будет корректным датировать его 1968 - началом 1969 года. Это второе из двух числящихся под данным архивным номером писем Шпаликова к Шепитько; первое имеет авторскую дату: 20 февраля 1968 года.

Несколько слов об этих письмах, о наиболее значимом в их содержании. В первом письме, написанном в Адлере от руки, синими чернилами, Шпаликов признается, что «выкинул» вторую половину сценария, ибо она «очень и очень личная и - при живых - не надо, не красиво» (л. 1); из контекста письма ясно, что под «личным» имеются в виду отношения с Наталией Рязанцевой, первой женой Шпаликова, с которой он расстался еще в начале 60-х. Далее Шпаликов пишет, что собирается включить в картину «поэтический ряд», поскольку «стихотворение $[. .]-$. это же целая сцена, эпизоды...» (л. 2); в картине «поэтического ряда» (то есть сопровождающих действие стихов) нет, но есть поэтичность, лиризм, вообще присущий сценариям Шпаликова (Застава Ильича, Я шагаю по Москве и др.). Здесь же он пишет, что работает еще и «с Лёшей Салтыковым [кинорежиссер А. Салтыков - А. К.], который сделает картину про

${ }^{1}$ См.: Г. Шпаликов, Я жил как жил. Стихи. Проза. Драматургия. Дневники. Письма, сост. Ю. А. Файт, Москва: Подкова 1998; Г. Шпаликов, Стихи. Песни. Сиенарии. Роман. Рассказы. Наброски. Дневники. Письма, сост. Л. Быков [текстология Ю. Файта], Екатеринбург: У-Фактория 1999; Г. Шпаликов, Пароход бельй-беленький, сост. А. Нехорошев, Москва: Эксмо-Пресс 1998 (впоследствии несколько раз переиздавалась под разными названиями).

${ }^{2}$ Мы лишь использовали цитату из него в кн.: А. Кулагин, Шпаликов, Москва: Молодая гвардия 2017, с. 224.

${ }^{3}$ Мы благодарны Павлу Константиновичу Финну за помощь в работе. 
любовь» (л. 3; об этом замысле нам больше ничего не известно), и, наконец, о том, что в Адлере находится футбольная команда минского Динамо во главе с тренером Севидовым, который «собирает бабочек [...] для обмена» (л. 5), чем очень удивляет Шпаликова.

Второе письмо, написанное - точнее сказать, отпечатанное на машинке - в Доме творчества кинематографистов в подмосковном Болшеве, посвящено большей частью одному житейскому недоразумению, неловкой ситуации, в которую Шпаликов по причине своей непосредственности попал и в которой теперь раскаивается. От творческих дел эта история далека, поэтому мы на ней не останавливаемся. Правда, в финале вновь заходит речь о будущей картине $T b l u$ я, и упоминается актер, который пробовался на одну из главных ролей (Петр), но в итоге так ее и не сыграл, «уступив» Леониду Дьячкову: «... я дал сценарий Володе Высоцкому - режиссерский, который у меня оставался. Разумеется, сама у него узнаешь, безо всяких предварительных заверений - для прочтения на всякий случай. Он тебе позвонит» (л. 8). Возможно, речь идет о встрече в Москве, а не в Болшеве. «Высоцкого в Болшеве, - вспоминает тот же П. К. Финн в письме к автору данной публикации (от 17 марта 2017 г.), - я видел, но ни разу одновременно с Геной». Факт встречи и передачи текста сценария дополняет картину личного и творческого общения двух больших художников, уже ставшую предметом изучения ${ }^{4}$.

И, наконец, сами стихи, ко второму письму приложенные. Они тоже отпечатаны на машинке и расположены на лл. 9-10. Приводим текст стихотворения, меняя прописные начальные буквы стихов на строчные (автор начинает прописными даже предложения в письме, то есть просто не считает нужным нажимать каждый раз соответствующую клавишу пишущей машинки):

\section{БАЛЛАДА ПРО ТИХОЕ ОТЧАЯНИЕ}

Лapuce

Тихое отчаяние на меня находило не раз,

Отчасти отчаяние было, как водолаз,

Но чем тише и глубже оно уходило во тьму,

Тем более и более я доверял ему.

Я болен, но не так, не тихим отчаянием,

Скрывающимся в траве,

Не таким, не нечаянным -

С февралем в голове, -

Не с Офелией, - дудочкой, черепом,

Не венком по воде, не пляшущим деревом,

А тем, тихим отчаянием, - не то что б,

${ }^{4}$ См.: Л. Надель, Владимир Высоикий и Геннадий Шпаликов, «В поисках Высоцкого» 2013, № 7 (янв.), с. 32-46. 
И, стоя, а не качанием,

Не пулей в лоб.

O, господи, был бы я верующий, а то атеист,

Вера моя - звери еще и чистый лист,

Отчетливое отчаяние, обыденность его,

Слова-то пустые: печальное, печенье - а то ли - чайная,

И ничего неохота, ни синего зимнего темного стекла,

Более того, - неохота, чтоб ночь текла,

А чтоб не кончалась, -

И более того - неохота,

Чтобы во сне лодка качалась,

Тоже - забота!

Ну, - покачай лодку. Еще чего?

Перебираясь неловко, -

А для кого?

И по той лодке, ловко, не ловко, - ладно

Без уловки, и без улова, -

Была б не баланда - ладно,

Иллюзии, иллюзии, - иллюзион.

Иллюзион смотреть - иллюзорно, -

Не зазорно,

Не стыдно, хотя б, -

Аллей - ап!

Нет, ни в коем случае - не зазорно,

Это все равно что спать на газете посреди газона

Или же ночевать на скамейке у окружного моста,

Идея проста, - можно спать между рельсами того же моста.

Всё это - в порядке вещей, - а вообще,

Тихое отчаяние - отвяжись,

Как нечаянная радость - возникни,

Вроде самофракийской Нике, - да, - вроде,

При всем честном народе, во саду ли в огороде

И с лошадью на броде, - тихое отчаяние,

Орет - ножи вилки точаем!

Кому - убыль,

А нам - прибыль.

Кому - рубль,

А кто выбыл.

Тихое отчаяние, - не масоны.

Надо - воду качаем,

Арифметике обучаем,

Венчаем, -

Тихое отчаяние приучено, приручено,

Всё к лучшему.

В стихотворении можно расслышать несколько мотивов, для Шпаликова важных. Прежде всего, сам лейтмотив его - отчаяние - показателен для той, фактически уже финальной, полосы жизни, в которую поэт и сценарист в эту пору, кажется, вступает и которая спустя шесть лет обернется трагическим уходом его из жизни. Житейская неустроенность и поэтическая неприкаянность - вот в какой комплекс настроений 
входит «тихое отчаяние» из Баллады..., выраженное «сбивчивым» ритмом - то раешным стихом («Надо - воду качаем, / Арифметике обучаем»), то стихом акцентным, заставляющим вспомнить опыт одного из любимых с юности поэтов Шпаликова - Маяковского (повлиявшего, впрочем, на очень многих молодых людей эпохи Оттепели). Особенно близок автору Балладыл.., как нам думается, «молодой» Маяковский, автор произведений типа Облака в штанах, с их героем - неприкаянным романтиком-максималистом. Показателен в Балладе... и лексический подбор - как бы нагромождение созвучных слов, по смыслу между собой никак не связанных: «Слова-то пустые: печальное, печенье - а то ли - чайная»; «И по той лодке, ловко, не ловко, - ладно / Без уловки, и без улова, - / Была б не баланда - ладно»; ср. с приведенной выше цитатой о «воде» и «арифметике». От этого возникает эффект «забалтывания», выдающий сбивчивость самого сознания лирического героя, вызванную тем же «отчаянием». В контексте же творчества Шпаликова Баллада... сродни таким стихотворениям как, например, Бессонница:

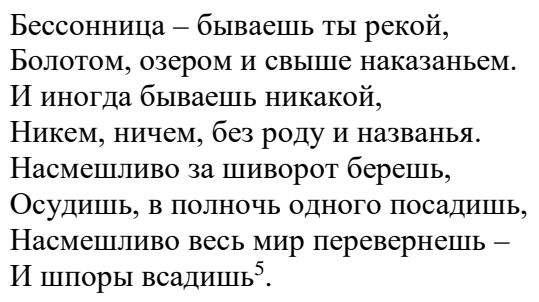

Бессонница - бываешь ты рекой, Болотом, озером и свыше наказаньем. И иногда бываешь никакой, Никем, ничем, без роду и названья. Насмешливо за шиворот берешь, Осудишь, в полночь одного посадишь, Насмешливо весь мир перевернешь И шпоры всадишь ${ }^{5}$.

Их сближает аллегорический характер негативного психологического состояния («Насмешливо за шиворот берешь»; «Тихое отчаяние - отвяжись»).

Кстати, об аллегоричности. Персонификация отвлеченного понятия («Тихое отчаяние - отвяжись») напоминает о фольклорной традиции. Известны народные песни о неотвязном горе, преследующем молодца, например: «А я от горя в темны леса - / А горе прежде век зашел; / А я от горя в почестный пир - / А горе зашел, впереди сидит» («А и горе, горегореваньице!..») 6 . Этот сюжет лег в основу литературной Повести о ГореЗлочастии XVII века; в годы школьной учебы Шпаликова она входила в школьную программу - и в его поколении отозвалась, кстати, вскоре еще у Высоцкого, в его песне Я несла свою Беду... (1970) ${ }^{7}$.

${ }^{5}$ Г. Шпаликов, Я жил как жил..., с. 307. Стихотворение, как и цитируемые ниже, не датировано.

${ }^{6}$ Русская народная поэзия. Лирическая поэзия, сост. Ал. Горелов. Ленинград: Художественная литература 1984, с. 242.

${ }^{7}$ См.: А. Е. Крылов, А. В. Кулагин, Высоикий как энииклопедия советской жизни. Комментарий к песням поэта, Москва: Булат 2010, с. 181-182. 
Строка «С февралем в голове» - своеобразная автореминисценция. В студенческую пору Шпаликов и учившийся на режиссерском факультете Андрей Тарковский, задумали, по свидетельству П. К. Финна ${ }^{8}$, написать сценарий именно под таким названием, но дальше замысла дело, судя по всему, не пошло. Упоминание Офелии и ее венка («венком по воде») имеет, кажется, реальную биографическую подоплеку. Экранизировавший на «Ленфильме» шекспировского Гамлета Г. Козинцев пригласил жену Шпаликова актрису Инну Гулая пробоваться на роль Офелии. Со слов Ю. А. Файта, друга Шпаликова, мы знаем, что на пробах Инна с недовольством отреагировала на то, что ей придется надевать на голову венок, и тем самым выдала свое незнание сюжета шекспировской трагедии. Этот казус и предрешил отказ Козинцева снимать ее в Гамлете (роль Офелии сыграла в картине А. Вертинская). Конечно, между съемками Гамлета (картина вышла на экран в 1964 году) и написанием стихотворения прошло несколько лет, но упомянутый эпизод, хорошо памятный другу Шпаликова, наверняка был хорошо памятен и ему самому. О шекспировской трагедии напоминают и соседние мотивы «дудочки» (флейта Гамлета), «черепа» (сцена с черепом шута на кладбище) и «пляшущего дерева» - то есть ивы, сук которой подломился, когда Офелия ухватилась за него, и увлек ее в воду реки. Правда, у Шекспира ива вовсе не «пляшущая», но такое гротескное преображение вполне допустимо в поэтическом мире Баллады про тихое отчаяние, где всё как бы перепутано и смещено (П. К. Финн предполагает, что в момент ее написания автор мог быть нетрезв).

Выражение «Вера моя - звери еще...» отсылает к тексту нескольких сценариев Шпаликова, где появляются животные. Так, в тексте 3aставы Ильича, опубликованном под названием Мне двадцать лет (напомним, что под этим названием фильм поначалу и вышел на экран), есть гротескный эпизод, где «вдоль бульвара медленно шел слон. Его прогуливал пожилой человек в теплых войлочных ботинках. Слон тоже был обут...» ${ }^{9}$ В фильме этого, конечно, нет. В сценарии Долгая счастливая жизнь перед едущим автобусом «заяц перебежал шоссе, вызвав своим появлением восторг и крики» ${ }^{10}$; в картине зайца «сменил» мелькнувший в кадре лось. Симпатичные зверюшки появляются в произведениях Шпаликова для детей - стихотворном сценарии мультфильма Сто ворон и сто сорок, и еще один сурок, в стихотворении «С утра по крыше ходит кот...», где звучит необычный тост «за всех котов, / В подвалах или в чаще, / За всех собак, моржей, китов, / К нам по утрам стучащих!» ${ }^{11}$. Можно привести и другие примеры, показывающие, что Шпаликов в самом

\footnotetext{
${ }^{8}$ См.: П. Финн, Конспект воспоминаний, «Искусство кино» 2015, № 3, с. 133.

${ }^{9}$ М. Хуциев, Г. Шпаликов, Мне двадияать лет. Сценарий, «Искусство кино» 1961,

${ }^{10}$ Г. Шпаликов, Я жил как жил ..., с. 349.

${ }^{11}$ Там же, с. 427.
} № 7 , c. 78 . 
деле неравнодушен к фауне, неожиданно появляющейся под его пером в шутливо-лирическом контексте.

Появление рядом с «иллюзиями» слова «иллюзион» могло быть подсказано не только общим корнем. Точнее, родственное слово «совпало» с названием московского кинотеатра «Иллюзион», на тот момент сравнительно недавно, в 1966 году, открытого. «Иллюзион» отличался от других кинотеатров тем, что в нем шли показы архивных лент, в том числе - зарубежных. Это было кино высокого уровня, кино интеллектуальное, как стали называть его впоследствии. Известно, что Шпаликов - как, впрочем, и многие кинематографисты его поколения - в юности испытал сильнейшее влияние итальянского и французского кинематографа (Аталанта Виго, Краснылй шар Ламорисса и др.). Это - возможный ассоциативный фон мотива «иллюзиона» в тексте Баллады ...

Особенно характерен для лирики - и для реальной биографии Шпаликова в заключительной ее поре - мотив бездомья и бродяжничества. В последние годы жизни Шпаликов так и жил, о чем вспоминают многие его современники ${ }^{12}$. Отношения с женой окончательно разладились, из семьи он ушел, ночуя то у одних знакомых, то у других, а днем бродил по городу, летом отдыхая на уличных скамейках, а зимой отогреваясь в почтовых отделениях, где наличие казенной ручки и почтовых бланков позволяло еще и писать стихи. Такова реальная основа следующих строк Балладыл...: «...спать на газете посреди газона / Или же ночевать на скамейке возле окружного моста...». Параллель им можно услышать в таких, например, шпаликовских стихах: «Я вижу вас, я помню вас / И эту улицу ночную, / Когда повсюду свет погас, / А я по городу кочую. / Прощай, Садовое кольцо, / Я опускаюсь, опускаюсь / И на высокое крыльцо / Чужого дома поднимаюсь» (Садовое кольцьо). Или: «Не принимай во мне участья / И не обманывай жильем, / Поскольку улица, отчасти, / Одна - спасение моё» (Не принимай во мне участья... $)^{13}$.

Думается, что Баллада про тихое отчаяние, впервые публикуемая здесь, будучи включена со временем в поэтические книги Шпаликова, займет в них одно из ключевых мест, ибо она аккумулирует в себе несколько ведущих мотивов творчества поэта и сценариста.

\footnotetext{
12 См., например: П. Финн, Конспект воспоминаний..., с. 151-153 и др.; Э. Корсунская, Книга для друзей, Москва: Современная экономика и право 2012, с. 14-35; О. Суркова, Письмо вослед, «Искусство кино» 2001, № 3, с. 138-147.

${ }^{13}$ Г. Шпаликов, Я жил как жил ..., с. 317, с. 318.
} 


\section{References}

Finn, Pavel K. „Konspekt vospominaniy”. Iskusstvo kino. № 3 (2015): 133, 151-153.

Khutsiev, Marlen M., Shpalikov, Gennady F. "Mne dvadtsat let. Stsenariy". Iskusstvo kino. № 7 (1961): 78.

Korsunskaya, Ella A. Kniga dla druzey. Moskva: Sovremennaya ekonomika i pravo, 2012: 14-35.

Krylov, Andrey E., Kulagin, Anatoly V. Vysotskiy kak entsiklopediya sovetskoy zhizni. Kommentariy k pesnyam poeta. Moskva: „Bulat”, 2010: 181-182.

Kulagin, Anatoly V. Shpalikov. Moskva: „Molodaya gvardiya”, 2017: 224.

Nadel, Lion. „Vladimir Vysotskiy i Gennady Shpalikov”. V poiskah Vysockogo. № 7 (yanv.) 2013: 32-46.

Russkaya narodnaya poeziya. Liricheskaya poeziya, sost. Al. Gorelov. Leningrad: "Khudozhestvennaya literatura”, 1984: 242.

Shpalikov, Gennady F. Ja zhil kak zhil. Stikhi. Proza. Dramaturgiya. Dnevniki. Pisma, sost. J. A. Fait, Moskva: „Podkova”, 1998.

Shpalikov, Gennady F. Parohod bely-belenkiy, sost. A. Nehoroshev, Moskva: „Exmo-Press”, 1998.

Shpalikov Gennady F. Stikhi. Pesni. Stsenariy. Roman. Rasskazy. Nabroski. Dnevniki. Pisma, sost. L. Bykov, Ekaterinburg: „U-Faktoriya”, 1999.

Surkova, Olga E. „Pismo vosled”. Iskusstvo kino. № 3 (2001): 138-147. 